


\title{
Parodia y autoparodia en El último lector de David Toscana
}

\author{
Diana Geraldo \\ El Colegio de México
}

Resumen:

La parodia y la autoparodia son dos de los recursos más relevantes que se presentan en El último lector de David Toscana. El uso de estos recursos permite explicar la visión crítica y desencantada del mundo que se ofrece en el texto por medio de la parodia de los manuales de escritura de novelas y de la crítica a la función del escritor en la sociedad; además de estos recursos, en el texto se plantean vínculos con la novelística mexicana y con la tradición bíblica, de modo que, junto con el discurso paródico, hay un procedimiento intertextual que sitúa al texto dentro de la tradición literaria y que, al mismo tiempo, permite a Toscana reformular los mecanismos estéticos de la novela mexicana.

Palabras clave: El último lector, Toscana, parodia, autoparodia, intertextualidad. 
Abstract

Parody and self-parody are two of the most relevant features of David Toscana's El último lector. These resources are means by which we can explain the critical and disenchanted world view that the text offers through parody of novel-writing manuals and criticism of the writer's function in society. Besides these features, there are links with the Mexican Novel and with the biblical tradition, so that, together with the parodic discourse, there is an intertextual procedure which places the text within the literary tradition and at the same time also allows Toscana to reformulate the aesthetic mecanisms of the Mexican Novel.

Keywords: El último lector, Toscana, Parody, Self-parody, Intertextuality

E

n El último lector, sexta novela escrita por David Toscana y universo ficcional que tiene, entre sus distintos temas, la parodización y la burla del mundo del libro. Desde la célebre obra de Cervantes, Don Quijote, la literatura ha sido explorada y analizada desde el interior del discurso ficcional, de tal modo que se ha elaborado un modo de juzgar la literatura desde los mismos textos. La lectura y la crítica de la novela, en semejanza con la parodia cervantina, son dos de los ejes narrativos que conforman esta obra de Toscana.

En el marco de la literatura mexicana moderna, la crítica y el análisis del mundo cultural, y con ello de la novela como uno de sus componentes, han sido planteados por varios autores; por ejemplo, la novela El miedo a los animales de Enrique Serna, en la que el autor se burla de un mundo degradado y corrupto mediante un ejercicio en el que los escritores y los funcionarios de la cultura aparecen convertidos en figuras grotescas y absurdas. Esta elaboración literaria permite a Serna poner de manifiesto su interés 
crítico sobre los ámbitos políticos y literarios. Las novelas de Ibargüengoitia, con su característico tono irónico, también subrayan vicios y defectos de la política, de la Revolución y de otros temas vinculados con el México del siglo pasado.

Aunque el pensamiento crítico y la burla, como ejercicios de exhibición despectiva, no son recursos literarios exclusivos del siglo XX, cabe aclarar, sí son una referencia importante que define el carácter de muchos de sus escritores. En esta línea es donde se sitúa El último lector de David Toscana. El objetivo de este artículo es explicar el carácter crítico de la novela, así como describir los elementos paródicos que participan en el cuestionamiento intrínseco del texto, en el que se expone una visión de mundo que media entre la ficcionalización, como forma de vida, según la perspectiva de los personajes, y la parodia, como recurso constructivo, que permite observar la visión crítica que se expone de ese mundo.

En El último lector de Toscana, se narran las condiciones de pobreza y de aislamiento en que se encuentra el bibliotecario Lucio, en un pequeño pueblo llamado Icamole, un lugar presuntamente localizado en el norte de México. La desaparición y la búsqueda policíaca de una niña son las dos circunstancias que dentro de la trama propician una conmoción en el pueblo. Este poblado se ubica en una zona desértica, aislada, y en el que la mayoría de sus personajes se presentan como seres hundidos en la rutina, monótona e infértil, como el mismo ambiente del lugar que está en correspondencia con la vida y las emociones de los personajes que habitan en él, quienes también tienen vidas estancadas en el aburrimiento debido a la falta de alteraciones o de sucesos inusitados en el pueblo. Para Gloria Prado, Toscana tiene vínculos intertextuales con la estética de Juan Rulfo, ya que "la ambientación y el tono en los que se desenvuelve la historia de su novela, evocan el mundo rulfiano de manera evidente" (2008: 303). En efecto, Icamole representa un mundo hostil, aislado, fuera del tiempo y del devenir histórico, 
con personajes que conviven con la vida y la muerte, la mayoría de las veces incapaces de marcar líneas de separación, aspectos que coinciden, en muchos momentos, con la vida de los habitantes de Comala. La investigadora considera, además, que la relación entre muerte-amor-locura es un elemento fundamental que une esta novela de Toscana con Pedro Páramo (2008: 306).

Todos estos aspectos de la trama participan en la construcción de la atmósfera planteada en el texto, la cual sostiene su escritura y su visión de mundo en la parodia como recurso constructivo. Conviene explicar de manera preliminar qué se entiende por parodia, antes de iniciar el análisis textual. En este trabajo, no pretendo propiciar un debate teórico respecto al concepto; por tal razón, planteo mi enfoque apoyándome en la propuesta de Linda Hutcheon, quien estudia la parodia como un género literario y la define de la siguiente manera:

La parodia no es un tropo como la ironía: se define normalmente no como fenómeno intratextual, sino como modalidad del canon de la intertextualidad.

Como las otras formas intertextuales (la alusión, el pastiche, la cita, la imitación y demás), la parodia efectúa una superposición de textos. En el nivel de su estructura formal, un texto paródico es la articulación de una síntesis, una incorporación de un texto parodiado (de segundo plano) en un texto parodiante, un engarce de lo viejo en lo nuevo (1992: 177).

Cuando Hutcheon habla del canon de la intertextualidad, está indicando que la parodia es una "modalidad" dentro del canon literario - modalidad en cuanto reactualización de los discursos de la tradición literaria- y que sus mecanismos están sujetos a la intertextualidad, pero para que exista verdaderamente el proceso intertextual es necesario el canon, pues sin éste no se puede efectuar el vínculo entre obras ni se pueden plantear relaciones o intercam- 
bios. Ahora bien, Hutcheon define el texto paródico quizá de una manera un poco tautológica, ya que considera que éste es la síntesis de un texto parodiado y de un texto parodiante, cuando en realidad el texto paródico es el texto parodiante. La definición quizá pueda aclararse si se precisa que la parodia, y no el texto paródico, es la síntesis del ejercicio de imbricación de un texto o discurso base, ella lo llama parodiado de segundo plano, que se incluye dentro de otro, el parodiante, la conjugación de ambos remite a la elaboración paródica. En todo caso, lo valioso de la argumentación de Hutcheon es que señala con precisión el funcionamiento de la parodia al explicar que su naturaleza estructural está determinada por el vínculo que se establece entre dos obras, textos o discursos, y que uno será el parodiado y el otro el parodiante.

La característica fundamental de la parodia es que siempre funciona en relación con otros textos literarios; en efecto, sus críticas o burlas siempre están dirigidas a otros discursos o a las convenciones literarias, ya que su campo de efectividad se encuentra en el mundo de la literatura y, por ello, opera de manera muy cercana a los procesos de intertextualidad. Este rasgo de la parodia, de alguna manera, está vinculado con la crítica, que en El último lector se manifiesta a partir de las lecturas que hace el bibliotecario Lucio. El gusto por la lectura que tiene el protagonista permite que se presente la burla y, con ella, la refuncionalización del género paródico, puesto que desde la perspectiva de Lucio se reflexiona sobre el quehacer literario; es innegable, sin embargo, que el texto está compuesto de humor, de un juego casi morboso - que raya a veces en la necrofilia - respecto a la muerte, a la literatura y al ser humano; además, todo esto está planteado desde la selección de lecturas de Lucio y desde los juicios de valor que éste emite al leer las novelas y, por eso, su perspectiva es la más relevante dentro del discurso. 
Aunque la dificultad para localizar los recursos paródicos en el texto haga parecer, a veces, que la contextualización literaria es mínima, es innegable que todo discurso paródico tiene elementos que hacen posible su identificación. Estos elementos son, en el caso de la novela aquí analizada, la personificación y descripción del bibliotecario, la burla de las novelas leídas por él, en la que las tramas y los títulos son una reformulación humorística de los discursos novelísticos que el protagonista lee y critica, e incluso, varios detalles de la vida rutinaria de los personajes parecen parodiar algunos relatos bíblicos.

En esta novela, la parodia es una táctica discursiva y retórica que transgrede el sistema de valores y desmitifica el objeto de su crítica. Se presenta como una forma refinada de lo lúdico, dado que está jugando con el lector. Este aspecto es sumamente importante, pues este recurso implica un contrato de lectura entre texto y receptor. Cualquier texto paródico espera un contacto entre lo dicho y lo entendido por el lector, es decir, se busca una respuesta, un entendimiento del juego propuesto por el autor. La parodia, en efecto, promueve una reflexión que va más allá del texto y reclama al lector pensar sobre lo dicho; en estos casos, el texto requiere de un lector que participe y sea un receptor activo. Este aspecto de la parodia está en relación con el título mismo de la novela de Toscana, El último lector, ya que desde su inicio el texto plantea la importancia de leer y de interpretar. Debido a este elemento de incitación, Ada Aurora Sánchez Peña señala que la lectura, como un acto de entrecruzamiento de subjetividades, es uno de los ejes temáticos de esta novela (2011: 26).

El último lector es un discurso diseñado para propiciar una reacción en el lector, pues entabla con éste un diálogo que va de la burla al humor negro, de lo lúdico a lo grotesco. Desde el título, el autor construye un discurso a la manera de una enredadera ficcional, donde se puede decir que el lector concreto es "el último lec- 
tor" de la novela, creando así una serie de conexiones internas, en la que Lucio es uno más de esos lectores planteados por Toscana en el discurso. El momento de interacción entre autor-lector sólo finalizará cuando se lea la última página. El párrafo final parece cerrar y, al mismo tiempo, confirmar el contrato de lectura que se fue dando en el transcurso de la narración; así concluye el texto: "habrá de reducirlo a la nada en una novela digna de infierno y cucarachas, habrá de sepultarlo en las arenas del mar o el desierto cada vez que alguien abra la última página de El último lector" (Toscana, 2004: 190).

Se plantea, así, la novela dentro de la novela, una mise en abyme que funciona como estructura rectora del texto. El autor construye un entramado ficcional compuesto por realidades paralelas que coexisten en la obra: la realidad narrada por Toscana, la realidad expuesta en las novelas que lee Lucio y la realidad que nosotros leemos como lectores reales. El texto está formado a la manera de las cajas chinas. El final de la novela parece cerrar el círculo de la narración, puesto que todas las realidades se reúnen en una sola representación: la ficción que se ideó en todo el relato y en la que la novela fue puesta en espejo dentro de sí misma, propiciando con esta construcción la burla y la parodia del propio texto.

El ejercicio paródico está ceñido, sobre todo, a la perspectiva de Lucio, el bibliotecario. Por esta razón, Miguel Rodríguez Lozano considera a este personaje un alter ego del propio autor (Rodríguez, 2006: 62), asunto que cobra importancia si concebimos a Lucio como una instancia ficcional de la mentalidad de Toscana, pues éste pone en voz del personaje una reflexión crítica que probablemente le pertenece. El bibliotecario se presenta como el inquisidor de las letras; su vida se reduce a leer y criticar libros. Como censor de la biblioteca se muestra intransigente y severo respecto a los textos: "el día que recibió la primera remesa de libros: quinientos siete ejemplares, de los cuales sólo ciento treinta habrían de pasar 
al librero. Los demás cargaron con el sello de censurado" (33). Este episodio recuerda la famosa escena de El Quijote cuando el cura y el barbero saquean la biblioteca del viejo caballero y donde, incluso, también se menciona La Galatea, otra obra de Cervantes. Toscana, a su vez, propone un ejercicio semejante en El último lector cuando se refiere a su propia novela Santa María del Circo. Esta mención de una obra anterior refuerza la idea de la mise en abyme que rige la estructura narrativa, lo mismo que en la escena de El Quijote; por tanto, esta alusión, aunque leve, es fundamental: indica que en ambas novelas (la de Cervantes y la de Toscana) los autores ponen en abismo otras obras suyas, proponiendo con este procedimiento una especie de autocrítica.

En varios apartados de la novela, se introducen los títulos y algunos fragmentos de las novelas que lee Lucio, los cuales complementan la narración total, de tal manera que el discurso es una especie de pastiche paródico de otros discursos novelísticos, en el que diversos registros e historias se superponen, a veces sin separación o límites entre ellos, hasta formar una conglomeración de discursos entre el relato de Toscana y los textos que lee Lucio, relatos que a su vez forman parte también de este universo narrativo en el que la realidad y la ficción pierden sus límites. Por esta razón, Lucio compara la vida con la literatura; para él, todo acto humano tiene su referencia literaria, como si escritura y vida estuvieran conectadas. Lucio lee el mundo, su mundo inmediato, su realidad, como el lector que lee un libro y, por ello, la comparación entre vida y literatura es esencial para percibir la visión de mundo que se halla detrás. Pongo sólo un ejemplo del texto respecto a este punto: "tu narración me agradó tanto que estaré pensando en ella un buen rato. Remigio resopla y se cruza de brazos. Para mi no es una narración, es la vida real, y no es cuestión de un rato, yo recordaré toda la vida el entierro de esa nińa. Lucio le pone la mano en el hombro. Habrá que borrar la retina y esto último que dijiste; bastante 
ordinario" (52, el subrayado es mío). Lucio dice esto después de escuchar a Remigio contar su experiencia con el cuerpo de la niña muerta. Como se ve, el tono y los comentarios de Lucio están expresados de manera similar a los que emite sobre los novelistas que examina en su biblioteca. Por tanto, el bibliotecario habla y critica la vida con la seriedad con que lee y juzga a los escritores, lo que permite pensar que, para los personajes de la novela, la frontera entre la realidad y la imaginación está desdibujada o, como explica Abeyta, "en El último lector se reivindica el papel de la imaginación que brota de la vida cotidiana" (Abeyta, 2010: 427).

En efecto, Lucio parece intuir su naturaleza ficcional, como los personajes onettianos que ven el mundo que los rodea y lo perciben como una ficción, como una irrealidad o como una farsa creada por un autor superior y externo a ese mundo. Esta especie de autoconciencia ficcional se confirma en la parte final de la novela cuando Lucio da a entender que se reconoce como un personaje que algún autor escribirá y cuyo título será "El último lector", como efectivamente sucede, lo cual sugiere que Lucio reconoce que es un personaje de este texto de Toscana, lo que confirma no sólo su ficcionalidad, sino la mise en abyme que rige toda la novela.

Cada fragmento de las novelas es leído por el bibliotecario y cada uno recibe su respectiva aprobación o censura. El último lector, expone en estos términos, y en boca de Lucio, la actitud de un lector y, siguiendo la idea del alter ego, de un escritor respecto a su mundo de creación, pero en el que la crítica también implica entender la literatura como parte de la vida, a la que también se inspecciona desde la perspectiva del bibliotecario protagonista.

Lucio descalifica, critica y se burla del oficio del literato, de la actividad profesional de los escritores, del lenguaje empleado por los narradores, de los cánones tradicionales y de todo lo que a su juicio es desdeñable en el ámbito de la cultura. La crítica va acompañada de mordacidad, sobre todo, cuando se describe la relación 
de Lucio con la literatura. Sin embargo, conviene preguntarse qué se esconde tras esas reprobaciones. Estas correcciones a las novelas pueden entenderse como una forma de parodiar los manuales de escritura, pues Lucio nos dice a la manera del escritor de manuales:

Una novela se ensucia menos cuando un lector come encima de ella que cuando el autor menciona la marca de los pantalones de un personaje o de su perfume o de su gafas o corbata o del vino francés que bebe en tal o cual restaurante; las novelas se manchan con la sola mención de una tarjeta de crédito, un automóvil o la televisión (60).

La imagen del narrador como un instructor de nuevos escritores, en este caso, resulta absurda, porque no se busca aleccionar sobre la buena literatura, sino criticar los errores comunes de los malos escritores. No obstante, es innegable que estos comentarios esconden una proposición tácita respecto al oficio de escribir novelas. Aunado a esto, está la personalidad de Lucio: un pobre hombre alejado de la civilización, un anacoreta frustrado, un viudo solitario alejado de las mujeres, un hombre sin dinero, sin comida, sin verdaderos lazos familiares. La caracterización de Lucio está definida de tal manera que complementa el carácter lúdico y crítico del texto; por eso, no representa al bibliotecario serio y estudioso proveniente de la ciudad, sino al campesino sin dinero y sin sustento que juzga el mundo intelectual desde su pequeño espacio desolado y hostil. La novela es, en este sentido, una parodia de los manuales que presumen enseñar lo que es bueno y lo que es malo en la escritura. En este caso, lo que se está planteando es el lugar desde donde se lleva a cabo la crítica literaria: no desde el encumbrado palco de la Academia, sino desde los polvorientos anaqueles de una biblioteca rural. Toscana está consciente del lugar del libro en la modernidad y de los cambios en el mercado editorial. Para Michael Abeyta, Toscana muestra una visión crítica de la cultura del libro 
en México e, incluso, afirma que "en sus novelas encontramos una crítica mordaz de la influencia del mercado estadounidense y los efectos negativos de la globalización" (2010: 434).

Mediante el recurso de la parodia, el texto tiene la posibilidad de mostrar irreverencia respecto a los discursos oficiales. Su crítica es visceral, porque impreca a las figuras más reconocidas de la tradición literaria. Así, en el mismo personaje se manifiesta esta actitud de antisolemnidad, que puede verse en la siguiente escena:

En el muro izquierdo, sobre una repisa y en torno a tres veladoras apagadas y una con llama, yace el frasco de vidrio con la carta del soldado Pedro Montes. Se trata de un cilindro de cristal que no se hace más angosto a la altura de la tapa; de hecho, ésta sobrepasa por poco el tamaño de la base. Lucio y Remigio van hacia allá. Siempre he pensado que el frasco original guardaba duraznos en almíbar, dice Lucio. El papel se sostiene pegado al cristal que le sirve como escaparate, de modo que la carta dirigida a Evangelina puede leerse de principio a fin. Una vez intenté quitar la tapa, dice Lucio, pero me fue imposible. Quiero abrirla porque Pedro Montes escribió fe con acento y en todos estos años parece que nadie se ha dado cuenta. Ya es hora de corregir el error, dice y saca de su bolsillo un marcador rojo [...] Lucio termina la faena, saca el papel y mira detenidamente la frase: tú me enseñaste a rezar y ahora que mi vida se acaba sólo me resta hacerlo con la fé de un niño. Alrededor del acento traza un círculo rojo, empalmándolo con las letras vecinas; después con la misma tinta, escribe entre paréntesis: fe no lleva acento aunque debamos acentuar nuestra fe (88-90).

La actitud del personaje hace más evidente la antisolemnnidad, pues al mancillar una reliquia histórica está trasgrediendo el límite de lo respetable. No es sólo una crítica a las reliquias anquilosadas — que pueden o no estar equivocadas_-, sino que el acto es irreverente en sí mismo; es, por eso, que en la actitud de Lucio se expresa el cuestionamiento y el carácter crítico de la novela, 
ya que el bibliotecario es quien reacciona mordazmente contra lo autorizado y lo reverenciado. Por ello, se considera un personaje que manifiesta el descreimiento y la altanería contra todo lo rigurosamente autoritario, incluso con una actitud de corrección del pasado, como si el personaje encarnara la reformulación moderna del pasado histórico, pues aunque el personaje cree que la carta del soldado está mal acentuada, debe considerarse que en el siglo XIX, y todavía en las primeras décadas del siglo XX, la norma ortográfica indicaba que debía acentuarse la palabra fe, ya que todos los monosílabos llevaban acento. Por tanto, esta actitud del personaje, más bien, apunta a una reescritura del pasado, es decir, una reescritura del discurso histórico, que en el momento actual en que vive Lucio consiste en corregir los aspectos que en el presente ya no tienen vigencia, y que están ejemplificados en esta novela mediante el simple problema de la ortografía. Para Rodríguez Lozano, este ejercicio de reescritura de la historia — que en El último lector también implica la intervención de Porfirio Díaz con su ejército en Icamole, como parte de la historia local que es, al mismo tiempo, la historia nacional—, tiene el objetivo de "regresar al pasado de México y verlo relacionado con el norte, o mejor, desde fuera del centro, y la trascendencia del lenguaje, de no hacer de éste un puro mecanismo de accesorio, logran en la narrativa de Toscana una simbiosis afortunada” (Rodríguez, 1999: 62).

En El último lector, se puede considerar, entonces, que la actitud de irreverencia del personaje responde, en primer lugar, a su condición de sujeto marginal, en contraste con la ciudad que representa una entidad de poder. De esta forma, se expresa la oposición entre ciudad y aldea. Esto ayuda a explicar por qué Lucio prefiere su pequeño pueblo Icamole y no Monterrey, que en este texto es la representación de la ciudad:

Fue la última noche antes de volver a Icamole. Tras varias cervezas Lucio se sintió en confianza para exponer sus gustos en materia de 
libros. El otro hombre escuchó casi sin hablar, bebiendo y echándose cacahuates a la boca. Cerca de la media noche se quitó una cáscara de entre los dientes para enjuiciar con aire superior. Tienes los tres complejos de un pueblerino: contra los gachupines, contra los gringos y contra las mujeres. Dio otro trago a la cerveza y continuó. En la ciudad ya superamos los primeros dos. Lucio dejó un billete sobre la mesa y se marchó. Juró que jamás asistiría a otra reunión de ésas ni pisaría de nuevo la ciudad de Monterrey o cualquier otra ciudad (116).

En segundo lugar, su actitud muestra irritación contra ambos polos: tanto la ciudad como la aldea son vistas con ironía y desprecio, a ambas se les ataca, pues así como desprecia a la gente de la ciudad, también se muestra grosero y altanero con los pueblerinos. Las ofensas contra el salvajismo, la ignorancia, la miseria y demás situaciones en las que vive su comunidad son también objetos de crítica, que coinciden en muchos casos con los vicios y defectos de los malos escritores o, simplemente, con la literatura. Así se continúa con la conciencia de ficcionalización que el personaje tiene de sí mismo y de su mundo: "El pueblo sin agua y yo sin comida. No está mal para un final de novela, se dice, la gente se va de Icamole y yo muero de hambre" (19).

Si intentamos llevar al extremo este razonamiento y si asumimos el carácter crítico y exploratorio de la novela, me parece que esta serie de acometidas contra la ciudad configuran la imagen del escritor opuesto al poder, que reconoce que se encuentra fuera del centro, en una geografía aislada, sin contacto con el progreso y la cultura. Bien podría pensarse, de nuevo, que las críticas de Lucio contra la ciudad y contra el pueblo son en realidad del propio autor, extendiendo la idea del alter ego autoral. Aun si no se realizan de manera intencional, estos ataques configuran la imagen de quien se considera en la periferia. El tono que adquiere la narración al exponer esta crítica recuerda la manera en que otras obras, y otros autores, 
han planteado este mismo recurso; por ejemplo, en la narrativa de Serna y en la de Ibargüengoitia, ya antes mencionados.

La visión paródica de la figura del autor y del lector no sólo implica la burla a su posición como escritor, sino que también demuestra la actitud crítica con que se perciben las acciones del gobierno respecto a la educación y a la lectura:

Una biblioteca en este lugar, dice mientras abarca el recinto con la vista o, mejor dicho, una bibliote. El teniente suelta una carcajada; Lucio se mantiene impávido para incomodar al visitante. No tienen clínica, pero tienen libros. ¿Quién entiende al gobierno? (61)

Como se muestra en la cita, las burlas y los acentos paródicos del discurso de El último lector configuran, dentro de la totalidad narrativa, una desaprobación de la política. Por eso, se pone en entredicho la responsabilidad del gobierno para ordenar las prioridades del pueblo. En este sentido, también se está sugiriendo que, antes que la literatura, existen otras necesidades de mayor importancia en el ámbito social. Una biblioteca en un lugar desolado, y con graves problemas económicos, plantea la posibilidad de un discurso paradójico. Desde la perspectiva de Lucio, se defiende la lectura y la literatura como parte esencial de la vida, pero, desde la perspectiva de los otros personajes, se insinúa que el gobierno se preocupa por cosas que no son urgentes, como la salud pública. Ambas ideas se contraponen: la visión de Lucio y la visión de los demás personajes, y de ahí resulta la postura paradójica elaborada en el texto. Es así que en la novela se va de un lado a otro reflexionando sobre el ejercicio de escribir y leer, y esto se hace mediante la burla y la parodia como mecanismos para la provocación y la desmitificación. La crítica a la novela es el asunto temático más sobresaliente de esta obra. La parodia impregna el sistema de valores 
del narrador (piénsese igualmente en Toscana), llegando al límite del nihilismo.

Otro objeto de crítica son los lectores, aspecto que se relaciona con la parodia de los manuales de escritura que mencioné antes. El lector, de acuerdo con Lucio, es mediocre si descalifica una novela por sus cualidades morales. Otra cosa sucede con las lectoras que, según el juicio de Lucio, no pueden leer sin aliarse de inmediato con las de su género. De este modo, se plantea una tipología de los lectores: voraces, despreocupados, ingenuos, inconscientes, etc., lo que seńala esta enumeración es la revisión que el texto plantea sobre el acto de lectura, con sus respectivas eficacias y deficiencias.

El último lector también puede concebirse, dado la riqueza de su enunciación y de su discurso, como una forma de autoparodia. El escritor y el lector son puestos en evidencia al delatar sus errores. Es innegable que David Toscana se reconoce a sí mismo como escritor, así que cuando señala las fallas de los demás, en sentido paradójico, está criticando su actividad, su forma de vida: se está burlando de sí mismo. La autoparodia deriva de los juicios y sentencias del personaje protagonista, en cuya representación se encuentra enmascarado el propio autor. La actitud crítica expuesta por Toscana está revestida de ironía, porque no quiere ser el inquisidor serio y ortodoxo, sino el juez bromista, pero juez finalmente. Toscana parece entender que parodiar es una forma de descalificar burlándose y haciendo risible lo denigrado, así sea él mismo; por eso, es capaz de mencionar su obra y de burlarse de ella: "Esto debe ir derecho a las tinieblas, Santa María del Circo, un melodrama sobre enanos y mujeres barbudas" (108). El mismo autor se vuelve objeto de crítica y de burla, como también ocurre en El Quijote de Cervantes, aunque en este último, Cervantes salva de la hoguera su obra La Galatea, que no es expuesta como objeto de burla. Esta posible conexión con el texto cervantino permite identificar la relación intertextual, en cuanto al recurso de la parodia, que es 
además un eje en Cervantes si consideramos que su obra es una parodia de las novelas de caballerías, así como de la puesta en abismo que ambos textos tienen como base de su enunciación.

El sentido de la autoparodia implica la trivialización de sí mismo, evidencia también de que existe un descreimiento o desconocimiento, una negación de sus raíces y de su identidad como escritor. $\mathrm{Al}$ dudar de los fundamentos que sustentan la vida artística de un escritor hace una crítica de los mismos, pues en este caso dudar es criticar. Si pone en duda las capacidades del novelista es porque, en realidad, está cuestionando esas supuestas capacidades.

Con el recurso de la autoparodia, Toscana está desmitificando su propia labor artística, pero no con fines reformativos ni con fines didácticos como la sátira, sino en sentido crítico, como una provocación. La novela, por ello, es una reacción crítica que resulta provocadora, porque su ejercicio caricaturiza y, con ello, se burla - voluntariamente o no- del ambiente literario.

En efecto, la diferencia es la marca más explícita de la parodia. En El último lector, esta forma de diferenciación está puesta en boca de Lucio, ya que es él quien subraya lo que considera erróneo, marcando así la oposición entre las obras y los tipos de lectores. Dicho en otros términos, la novela plantea una visión de mundo en términos risibles que el narrador, desde la perspectiva de Lucio, transmite al lector.

Una forma más de la parodia se expresa en el constante entrecruzamiento de novelas y fragmentos novelísticos que apuntan a la representación de la tradición literaria. Con el uso de la parodia, el narrador se burla de esa herencia. Por ejemplo, con el apelativo Melquisedec, nombre que tiene relación con el personaje bíblico, se introduce dentro del texto la posible parodia del discurso bíblico como un intertexto del relato. En la novela, este juego paródico se presenta cuando se hace una equiparación entre este discurso y la fundación del norte de México. Icamole parece tener 
una fundación similar a la acontecida en la tradición del cristianismo, debido a que en la novela se retoma el discurso fundacional más importante de Occidente y se compara con la de este pueblo, para así cimentar este lugar de acción como si también tuviera un pasado igualmente glorioso, pero lo hace mediante la parodia, para así crear el efecto de antisolemnidad, que es el tono empleado en toda la novela.

Lo mismo sucede cuando se parodia el éxodo de los habitantes del pueblo, cuya salida remite al de los judíos. La parodia del intertexto bíblico se presenta, incluso, en la reformulación del lenguaje religioso y de las frases más fácilmente reconocibles de la tradición cristiana. Pongo un ejemplo: "Abre la cortinilla y por el hueco arroja El otoño en Madrid. No lo perdones, señor, dice, porque sabía lo que hacía” (27). El intertexto bíblico es un vínculo más de Toscana con Rulfo, pues este último también dialoga con la cosmovisión cristiana en su novela Pedro Paramo.

En El último lector se plantea, también, una crítica sobre la intervención de las figuras autoritarias de la política en el ambiente intelectual, incluso podría pensarse que les da un tratamiento a la manera de Serna en El miedo a los animales. Así se presenta en la obra de Toscana:

Lo patea y de paso le mienta la madre a cualquier presidente, ex mandatario, diputado o embajador que se hizo pasar por novelista sin soltar jamás su copita de vino ni haberse ensuciado los pies en cualquiera de los incontables Icamoles de este país (187).

Esta última frase expone la visión crítica del texto: ataca a la figura del escritor y a la autoridad política (en este caso, el gobierno), parodia una tradición literaria, y de paso critica la miseria intelectual de nuestro país. El verbo ensuciarse implica dos cosas en este contexto de la novela: primero, que los sujetos de poder no viven la experiencia cotidiana, pero que sí la alaban sin conocerla y sin haber 
experimentado su situación; segundo, indica que el pueblo vive en situaciones que lo mantienen en la opresión y en la ignorancia. La frase "Los incontables Icamoles" formula la idea de que en México muchos pueblos padecen las mismas situaciones problemáticas, de tal modo que este Icamole ficcional tiene circunstancias que engloban las condiciones de otros pueblos del país.

En resumen, la parodia es un recurso literario efectivo, tanto para criticar algunos aspectos que conforman a los discursos más representativos del canon literario como para burlarse del ambiente intelectual-literario. Por tanto, con este género literario se configura un discurso de carácter crítico-burlesco. La parodia sostiene la escritura y la visión de mundo, pero al mismo tiempo provoca la autoparodia, ya que ésta es útil como herramienta retórica de crítica. El último lector es una parodia del mundo de las letras y es, también, una reflexión de todo lo que conforma ese mundo, empezando por el autor mismo.

\section{Bibliografía}

Abeyta, Michael, 2010, "El humor negro, la burla de la modernidad y la economía del libro en la narrativa de David Toscana", Revista de Critica Literaria Latinoamericana, año 36, núm. 72, pp. 415-436.

Hutcheon, Linda, 1992, "Ironía, sátira, parodia. Una aproximación pragmática a la ironía”, en De la ironia a lo grotesco (en algunos textos literarios hispanoamericanos), México, UAM, pp. 173-193.

Prado Garduño, Gloria, 2008, "En el páramo ensońado: entre dos Susanas, Comala, Icamole y Pedralbes, en "Pedro Páramo". Diálogos en contrapunto (1955-2005), Yvette Jiménez de Báez y Luzelena Gutiérrez de Velasco (eds.), México, El Colegio de México / Fundación para las Letras Mexicanas, pp. 301-309. 
Rodríguez Lozano, Miguel G., 2006, "Notas sobre Duelo por Miguel Pruneda y El último lector de David Toscana", Revista de literatura mexicana contemporánea, núm. 31, pp. 59-64. , 1999, "La otra experiencia del norte: aproximación a la narrativa de David Toscana", Revista de literatura mexicana contemporánea, núm. 10, pp. 57-66.

Sánchez Peña, Ada Aurora, 2011, "El último lector de David Toscana o la lectura como revelación”, La colmena, núm. 70, pp. 26-31. Toscana, David, 2004, El último lector, México, Mondadori.

(Recibido: 17 de diciembre de 2014, aceptado: 6 de marzo de 2015) 